\title{
ALTERAÇÕES ÓSSEAS NO DESENVOLVIMENTO DA ACONDROPLASIA
}

\begin{abstract}
Ana Carolina Mello Fontoura de Souza1, ORCID ID 0000-0003-2324-1301; Bruna Karas' ORCID ID 0000-00031301-9256, Camilla Mattia Calixto' ORCID ID 0000-0001-5464-0837; Gabriela Pires Corrêa Pinto', ORCID ID 0000-0003-4471-0613; Julia Henneberg Hessman1, ORCID ID 0000-0002-9310-4508; Gabriela Dias Silva Dutra Macedo², ORCID ID 0000-0002-2245-2732
\end{abstract}

\section{FILIAÇÃO}

(1) Universidade Estadual de Ponta Grossa, Departamento de Medicina, Acadêmica de Medicina

(2) Universidade da Região de Joinville (UNIVILLE), Departamento de Medicina, Graduada em Medicina

\section{AUTOR CORRESPONDENTE}

Ana Carolina Mello Fontoura de Souza; acmfs00@gmail.com; Av. Ernani Batísta Rosas, 3131 - Jardim Carvalho, Ponta Grossa - PR, 84015-900. Bloco 25B Apartamento 37; Universidade Estadual de Ponta Grossa,

Departamento de Medicina.

\section{MENSAGENS-CHAVE}

A acondroplasia, como tipo mais comum de nanismo, afeta uma parcela substancial dos nascidos vivos atualmente;

Ainda há escassez de trabalhos que evidenciem, de forma unificada, as alterações radiológicas e de imagem; Esse trabalho atualiza achados sobre o diagnóstico da acondroplasia, ressaltando as alterações ósseas em exames de imagem em um único texto;

O presente estudo corrobora com o melhor diagnóstico dos pacientes portadores da doença.

\section{RESUMO}

INTRODUÇÃO: A acondroplasia, o tipo mais comum de nanismo, é uma displasia óssea que afeta 1 para cada 15000 a 40000 nascidos vivos, caracterizada por uma mutação no gene do fator de crescimento de fibroblastos (FGFR3). Esse trabalho tem como objetivo evidenciar as alterações ósseas presentes na acondroplasia e os possíveis achados radiológicos. MÉTODOS: Revisão narrativa de literatura realizada de abril a junho de 2019, selecionando 42 artigos das bases de dados Scielo, Biblioteca Virtual de Saúde (BVS) e MEDLINE/Pubmed. Também foram consultados quatro livros. RESULTADOS: Inúmeras alterações ósseas foram encontradas nos indivíduos acondroplásicos. Foram observados no crânio: diminuição do diâmetro do forame magno, desproporção entre viscerocrânio e neurocrânio, dentição apinhada, prognatismo mandibular, ponte nasal deprimida, osso frontal proeminente e hipoplasia central da face. Na coluna, os pedículos vertebrais são mais curtos, ocorre estenose do canal vertebral, cifose lombar, hiperlordose e escoliose. A pelve apresenta espinhas isquiáticas pequenas e deprimidas, extremidades do ílio arredondadas, fossa ilíaca em formato quadrado e teto acetabular horizontal. O sacro é estreito e horizontalizado. Nos membros, destaca-se o encurtamento rizomélico e as proeminências dos acidentes ósseos. Ocorre supercrescimento fibular, com angulação anterior tibial, incapacidade de eversão do pé e Genu Varum. No membro superior, a cabeça radial é achatada, limitando a movimentação do cotovelo. As mãos são em tridente, com falanges proximais curtas e deformidades metacarpais. A caixa torácica é pequena, porém ampla, com costelas curtas, de extremidades anteriores alargadas. DISCUSSÃO: As modificações mencionadas corroboram os achados clínicos e radiológicos no diagnóstico por meio de ultrassonografias a partir da vigésima semana gestacional e por radiografias após o nascimento. CONCLUSÃO: Das alterações descritas, destacam-se as do crânio, coluna vertebral, pelve, membros e tórax. Ainda há a necessidade de estudos mais completos sobre o tema.

PALAVRAS-CHAVE: Acondroplasia; Diagnóstico por imagem; Radiografia; Doenças do desenvolvimento ósseo; Nanismo.

\footnotetext{
ABSTRACT

INTRODUCTION: Achondroplasia, the most common type of dwarfism, is a bone dysplasia that affects 1 in every 15000 to 40000 live births, characterized by a mutation in the fibroblast growth factor gene (FGFR3). This paper aims to highlight the bone changes present in achondroplasia and the possible radiological findings. METHODS: Narrative review of literature conducted from April to June 2019, selecting 42 articles from the Scielo, Virtual Health Library (VHL) and MEDLINE/Pubmed databases. Four books were also consulted. RESULTS: Numerous bone changes were found in achondroplastic individuals. The following were observed in the skull: decreased diameter of the foramen magnum, disproportion between viscerocranium and neurocranium, crowded dentition, mandibular prognathism, depressed nasal bridge, prominent frontal bone and central
} 
hypoplasia of the face. In the spine, the vertebral pedicles are shorter, vertebral canal stenosis, lumbar kyphosis, hyperlordosis, and scoliosis occur. The pelvis presents small and depressed ischial spines, rounded iliac ends, a square-shaped iliac fossa, and a horizontal acetabular roof. The sacrum is narrowed and horizontal. In the limbs, rhizomelic shortening and bony prominences stand out. Fibular overgrowth occurs, with anterior tibial angulation, inability to reverse the foot, and genu varum. In the upper limb, the radial head is flattened, limiting movement of the elbow. The hands are trident shaped, with short proximal phalanges and metacarpal deformities. The rib cage is small but broad, with short ribs and broadened anterior extremities. DISCUSSION: The modifications mentioned corroborate the clinical and radiological findings in the diagnosis by ultrasonography from the twentieth gestational week and by radiography after birth. CONCLUSION: Of the changes described, those of the skull, spine, pelvis, limbs and chest stand out. There is still a need for more complete studies on the subject.

KEYWORDS: Achondroplasia; Diagnostic Imaging; Radiography; Developmental Bone Diseases; Dwarfism.

\section{INTRODUÇÃO}

A acondroplasia é uma displasia óssea resultante de uma mutação autossômica dominante, de penetrância completa, no gene do fator de crescimento de fibroblastos (FGFR3), que leva a alterações do desenvolvimento de cartilagens por ossificação endocondral $(1,2)$. A taxa de incidência estimada da acondroplasia é de 1 para cada 15000 a 40000 nascidos vivos (3). De acordo com o estudo colaborativo latino-americano de malformações congênitas (ECLAMC), realizado por Orioli em 1986 (4), estima-se que a incidência seja de 1 para 23000 na América do Sul.

A acondroplasia é o tipo de nanismo mais frequente, sendo o fenótipo caracterizado por lordose lombar, protuberância abdominal, encurtamento rizomélico, ou seja, da raiz dos membros, e deformidades craniofaciais, como: mandíbula frontal e hipoplasia mediana grave (5). Ao nascimento, a estatura média em meninos é de $47,7 \mathrm{~cm}$ e em meninas é de 47,2 cm (6). Já a altura final fica entre 115 e $137 \mathrm{~cm}$ em mulheres e de 120 a $145 \mathrm{~cm}$ em homens (7). Em contrapartida, o peso médio dos indivíduos adultos é de 55 $\mathrm{kg}$ para os homens e $46 \mathrm{~kg}$ para as mulheres, com tendência para a obesidade (6).

Há testes genéticos de mutação para a acondroplasia que podem ser úteis, embora o diagnóstico geral usualmente seja feito clinicamente (8). Os pacientes afetados são reconhecidos em $79 \%$ no pós-parto e em $94 \%$ após o primeiro ano de vida (7). No geral, o diagnóstico intrauterino é feito por meio de ultrassonografia, sendo raramente perceptível antes da vigésima semana gestacional (9). Radiografias esqueléticas também são métodos afirmativos

Figura 2- Horizontalização sacral (14)

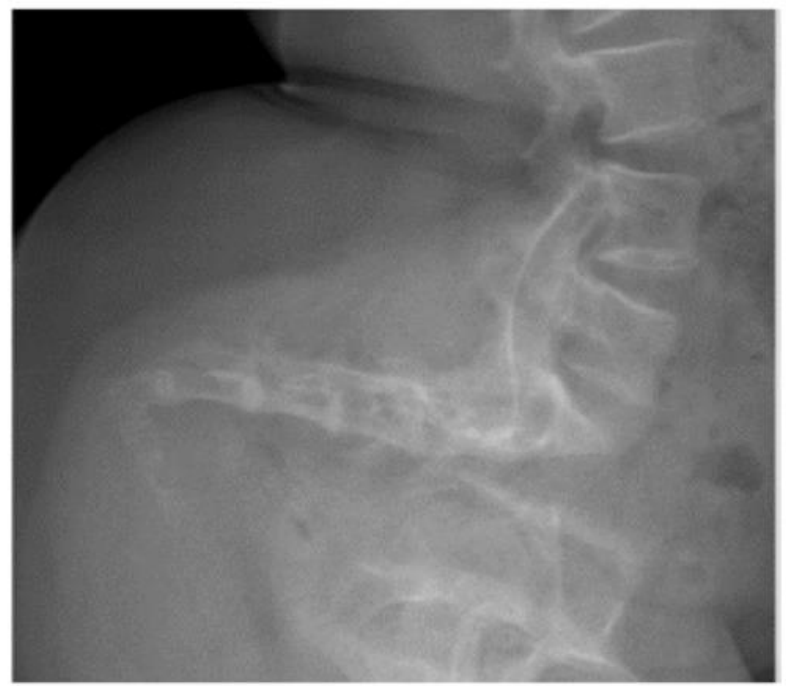

para a displasia, a partir de critérios específicos de idade (10). Além da estatura, radiografias e ultrassonografias, o peso e o perímetro cefálico também são utilizados para um diagnóstico preciso (7). O objetivo dessa revisão narrativa de literatura é, portanto, apresentar as principais alterações e malformações ósseas relatadas em pacientes acondroplásicos.

\section{MÉTODOS}

Esta revisão narrativa de literatura foi realizada no período de abril a junho de 2019, utilizando artigos e livros para a redação. Os trabalhos selecionados constavam nas bases de dados Scielo, MEDLINE/Pubmed e na Biblioteca Virtual de Saúde (BVS). A fim de esclarecer e reunir as principais alterações ósseas e radiográficas descritas na literatura em pacientes com acondroplasia, foram utilizados os descritores: "achondroplasia", "diagnostic imaging", "diagnosis" e "bone development", agrupados em: "achondroplasia and diagnostic imaging", "achondroplasia and diagnosis" e "achondroplasia and bone development".

Para a primeira combinação, na base de dados Scielo e na BVS, não foram encontrados resultados. No MEDLINE/Pubmed, a pesquisa "achondroplasia and diagnostic imaging" apresentou 184 resultados. Para a segunda combinação, foram encontrados oito resultados no Scielo, 255 na BVS e 350 no MEDLINE/Pubmed. Por fim, os últimos termos apresentaram 63 resultados na BVS, 24 no Scielo e 99 no MEDLINE/Pubmed. Ainda, no MEDLINE/Pubmed e na BVS, foi utilizado adicionalmente o descritor "achondroplasia and complications", com a apresentação de 173 resultados no MEDLINE/Pubmed e 120 resultados na BVS. Ao final, foram selecionados dois artigos no Scielo, três na BVS e quatorze no MEDLINE/Pubmed.

Os critérios de inclusão foram a linguagem, em português, inglês e espanhol e a leitura dos resumos dos artigos, selecionando-se somente os que evidenciaram que o tema tratado seria específico sobre as alterações ósseas ou de exames de imagem dos pacientes com acondroplasia. Foram excluídos artigos que descreviam somente as alterações funcionais ou manifestações clínicas dos pacientes com acondroplasia; estudos limitados às alterações psicossociais desses indivíduos; trabalhos relacionados apenas aos aspectos genéticos da doença ou à epidemiologia da acondroplasia, ou seja, excluindo-se aqueles que não se adaptaram ao tema escolhido ou tratavam de aspectos do tema que não seriam abordados nesta revisão.

Para as pesquisas feitas no MEDLINE/Pubmed, foi usado o 
filtro "há dez anos", escolhendo, assim, os artigos publicados a partir de 2009. Já na BVS, foram selecionados artigos publicados a partir de 2010. No Scielo não foi necessária a utilização de filtros temporais. Além disso, foram selecionados outros 23 artigos encontrados a partir de buscas específicas, totalizando 42 artigos. Como forma de complementar conceitos, foram utilizados quatro livros da área de Ortopedia, Anatomia Humana, Pediatria e Embriologia, disponíveis na Biblioteca Central Professor Faris Michaele e na Biblioteca do Hospital Universitário da Universidade Estadual de Ponta Grossa.

Dentre os artigos encontrados sobre o tema, poucos reuniram o conhecimento sobre as deformidades ósseas em um único documento, apenas descreveram as alterações de um segmento corporal ou então as relacionaram com as alterações funcionais, não abordadas neste trabalho. Portanto, o desenho que melhor se adaptou ao trabalho foi o de uma revisão literária narrativa, a fim de agrupar todos esses pontos, relevantes no diagnóstico da acondroplasia.

\section{RESULTADOS}

As características craniofaciais dos indivíduos acondroplásicos foram relatadas em diferentes artigos científicos, incluindo alterações no viscerocrânio (maxila, mandíbula, nariz, cavidade nasal e cavidade orbital) e neurocrânio (frontal, etmoide, esfenoide, occipital, temporal e parietal), principalmente devido à craniossinostose $(3,11)$. O gene FGFR3, responsável pela sinalização do crescimento e remodelação óssea, regula a proliferação condrocítica na

Figura 1- Desproporção entre neurocrânio e viscerocrânio e bossa frontal (7)

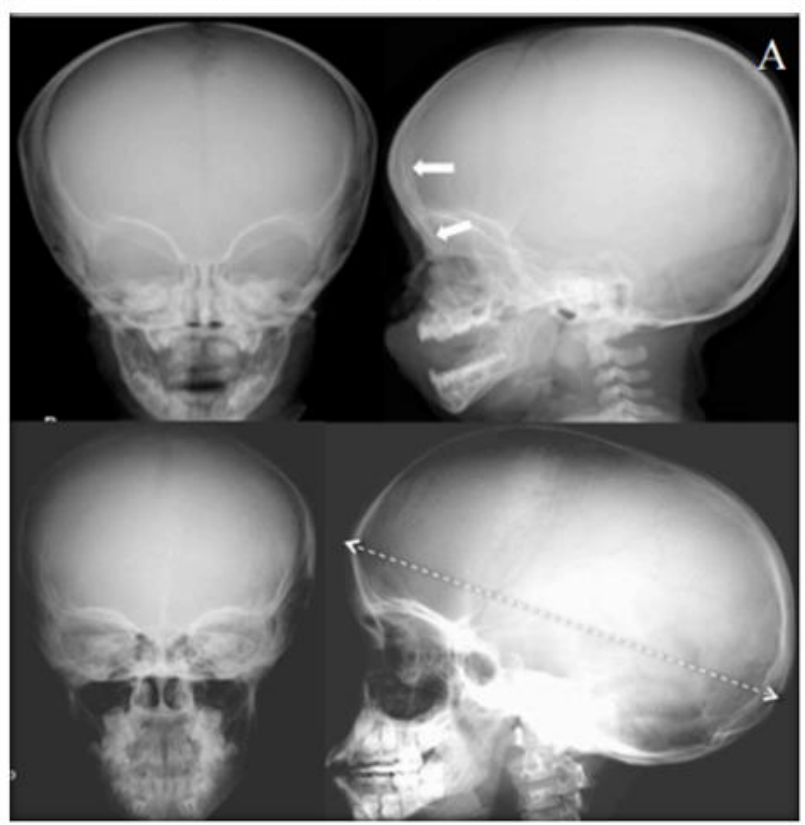

placa de crescimento de cartilagem (1, 2). Quando mutado, como na acondroplasia, perde essa habilidade, causando uma disfunção na ossificação endocondral dos ossos da base do crânio. Dessa forma, os ossos de formação intramembranosa têm crescimento relativamente normal, como na calvária (12). A ossificação intramembranosa difere da endocondral pois a ossificação direta acontece somente no período fetal, sobre um molde mesenquimal já formado no período embrionário (3). Isso gera uma grande desproporção entre o viscerocrânio e o neurocrânio (Figura 1). Os ossos de tamanho normal incluem: temporal, zigomático, mandíbula e calvária (13).

Outras alterações também são causadas devido ao encurtamento da base do crânio, sem relação direta com o tipo de ossificação. Assim, os ossos do viscerocrânio, mesmo apresentando ossificação intramembranosa, podem ter tamanho diminuído, causando uma hipoplasia da porção central da face. Da mesma maneira, as deformidades do viscerocrânio envolvem a bossa frontal (osso frontal proeminente), achatamento do osso nasal, depressão da ponte nasal, nariz em sela e estreitamento das vias aéreas. Além disso, é observada uma hiperplasia mandibular com crescimento desproporcional, além de uma hipoplasia maxilar (14). O palato anterior é encurtado, causando diversas alterações dentárias, incluindo apinhamento dentário, maloclusão, retrognatismo maxilar, prognatismo mandibular, discrepância do tamanho dos arcos dentários e atrasos na erupção dos dentes (14-16). Por outro lado, deformidades no neurocrânio abrangem uma calvária volumosa e craniossinostose $(14,16)$

As alterações da base do crânio compreendem a base encurtada e um ângulo agudo. O forame magno possui dimensões sagital e transversal diminuídas, com formato de chave. Pode ocorrer uma occipitalização do atlas, prejudicando a mobilidade cervical e a parte petrosa do osso temporal apresenta angulação aumentada, prejudicando o alinhamento dos ossículos auditivos, causando uma mudança na forma e direção dos tubos auditivos (14).

Em relação à craniossinostose, destacam-se as suturas esfenoparietal, as do esfenoide e as do occipital (17). As suturas esfenoparietais fecham-se no indivíduo não acometido aos vinte anos, enquanto que, nos acondroplásicos, ela começa a se fechar aos dois anos, estando totalmente ocluída aos dez anos (5). As alterações no tamanho da base do crânio estão relacionadas com a ossificação endocondral do osso occipital. Nele, a cartilagem paracordal, que se forma ao redor da extremidade cranial da notocorda, funde-se com as cartilagens derivadas das regiões do esclerótomo dos somitos occipitais. A junção dessas cartilagens estrutura a base do osso occipital, que inclui o forame magno. Este acidente é formado por meio de extensões que crescem ao redor da extremidade cranial da medula (13). Como o crescimento do occipital é diminuído devido às alterações do gene FGFR3, o forame magno também é hipoplásico $(9,13)$. Aliado a isso, observa-se que o processo odontoide tende a se projetar posterior e superiormente no forame magno (7). Isso acarreta uma estenose da junção craniocervical (5).

Esse estreitamento gera complicações, como uma compressão medular, que pode causar apneia do sono, alterações cardiorrespiratórias, mielopatias, siringomielia e hidrocefalia (18). Também pode ocorrer hipotonia muscular, principalmente em crianças (19). Além disso, foi observada uma taxa de $7,5 \%$ de morte em indivíduos de até um ano de idade em decorrência da compressão do tronco cerebral na junção craniocervical (20).

Em alguns indivíduos, foi observado o forame em forma de 
"chave", além de possuir as dimensões diminuídas. O estreitamento do forame magno provoca aumento da pressão venosa no crânio, causando hidrocefalia e aumento da pressão intracraniana. Como nas crianças com acondroplasia as fontanelas obliteram-se tardiamente, essa hipertensão contribui para o aumento do tamanho do neurocrânio em relação ao viscerocrânio.

No que diz respeito às alterações dentárias, algumas das principais consequências são: dificuldades na higiene bucal, gengivite e alterações na fala. As maloclusões podem incluir a mordida aberta e a mordida cruzada (15). O atraso na erupção dentária ocorre devido à falta de espaço no arco dentário $(15,21)$.

Quanto às deformidades da parte petrosa do osso temporal, destaca-se o aumento da angulação. Em indivíduos não acondroplásicos, a angulação é de $8^{\circ}$ a $10^{\circ}$, enquanto que, nos acondroplásicos, ela pode aumentar em 40ำ (22). Isso induz a um mau posicionamento dos ossículos auditivos e do seu alinhamento, além de alterar a forma e a direção dos tubos auditivos, causando otites recorrentes $(23,24)$. Perda auditiva e atrasos na fala são relatados em $17 \%$ dos pacientes com até cinco anos de idade (25).

No que concerne às deformidades faciais, ocorre deficiência no crescimento do terço médio facial, ocasionando uma obstrução das vias aéreas $(26,27)$. Com relação à face, pode-se dizer também que a bossa frontal, aliada à depressão da ponte nasal e o prognatismo mandibular fazem com que a fronte, o nariz e o mento estejam alinhados no mesmo plano anatômico (14).

Ainda, na maioria dos pacientes acondroplásicos, foram observadas alterações comuns no formato e na distribuição das vértebras.

Dentre essas características, destacam-se as deformidades no corpo vertebral, como o espessamento e o encurtamento dos pedículos vertebrais em seus diâmetros anteroposteriores. Já a distância interpedicular, na maioria dos acometidos apresenta-se mais estreita no nível de L5 em comparação ao nível de L1. Ocasionalmente, essa distância pode ser a mesma em toda a coluna lombar. Em indivíduos normais, a distância interpedicular aumenta da extremidade cervical para a lombar. Assim, a radiografia anteroposterior da coluna é um exame complementar diagnóstico para a acondroplasia (28).

Tais alterações presentes nos pedículos vertebrais contribuem para a estenose do canal vertebral. A redução do diâmetro do canal espinal ósseo, particularmente na região lombar, pode ocasionar dor lombar, claudicação radicular e ciática e parestesia (19). Foi observada, também, hiperreflexia de membros inferiores (29).

Foram observadas, conjuntamente, deformidades características nos corpos vertebrais, como uma configuração côncava do aspecto posterior dos corpos das vértebras. Os corpos vertebrais são estreitos no sentido anteroposterior, porém não há alterações na altura, o que causa uma desproporção dimensional (28). Em sua face anterior, diz-se que o formato do corpo vertebral é em "bala", ou em "gancho", por uma proeminência da região central (9). Do mesmo modo, são comuns os osteófitos e em alguns indivíduos foi observada artrite degenerativa, compatível com a idade (23).

Em indivíduos acondroplásicos também é comum a presença de alterações de curvatura, como cifose toracolombar a nível de T8 a L4, acometendo indivíduos na primeira infância e regredindo com o aumento do tônus muscular (6). Esta cifose não está relacionada a nenhuma anormalidade das vértebras individuais, mas a sua angulação. No recém-nascido, a curvatura varia de $15^{\circ}$ a $25^{\circ}$, progredindo para $60^{\circ}$ a $70^{\circ}$ (28). Assim que a criança desenvolve a posição ortostática e inicia a deambulação, o nível inferior da curva muda de L4 a L3 e o superior chega a T8 ou T10. O ápice normalmente localiza-se em L2 (30).

Segundo Margalit et al. (31), foi comprovada a presença de cifose toracolombar em $89 \%$ das crianças acondroplásicas com menos de três anos, sendo que 30\% mantiveram a curvatura anormal na vida adulta. A partir dos três anos, a cifose inicia uma regressão, no entanto, a partir dos 10 anos, esse decréscimo torna-se insignificante $(30,32)$. Este estudo ressaltou, portanto, a relevância da cifose toracolombar nos acondroplásicos, que pode ser, associada a outros critérios, usada como complemento ao diagnóstico. Além disso, apesar de alguns apresentarem regressão, outros ainda mantém essa característica, que se torna prejudicial a longo prazo (31). O estudo conduzido por Borkhuu et al. (30) indicou que o atraso no desenvolvimento motor foi significativamente associado à progressão da cifose, uma vez que houve um aumento significativo na progressão do ângulo em mais de 20 ํ em crianças que deambularam após uma média de 24 meses, em comparação com as crianças que começaram a andar pela média dos dezoito meses. Foi notada uma incapacidade desses indivíduos de sentar-se sem apoio até

Figura 3- Encurtamento rizomélico dos membros (37)

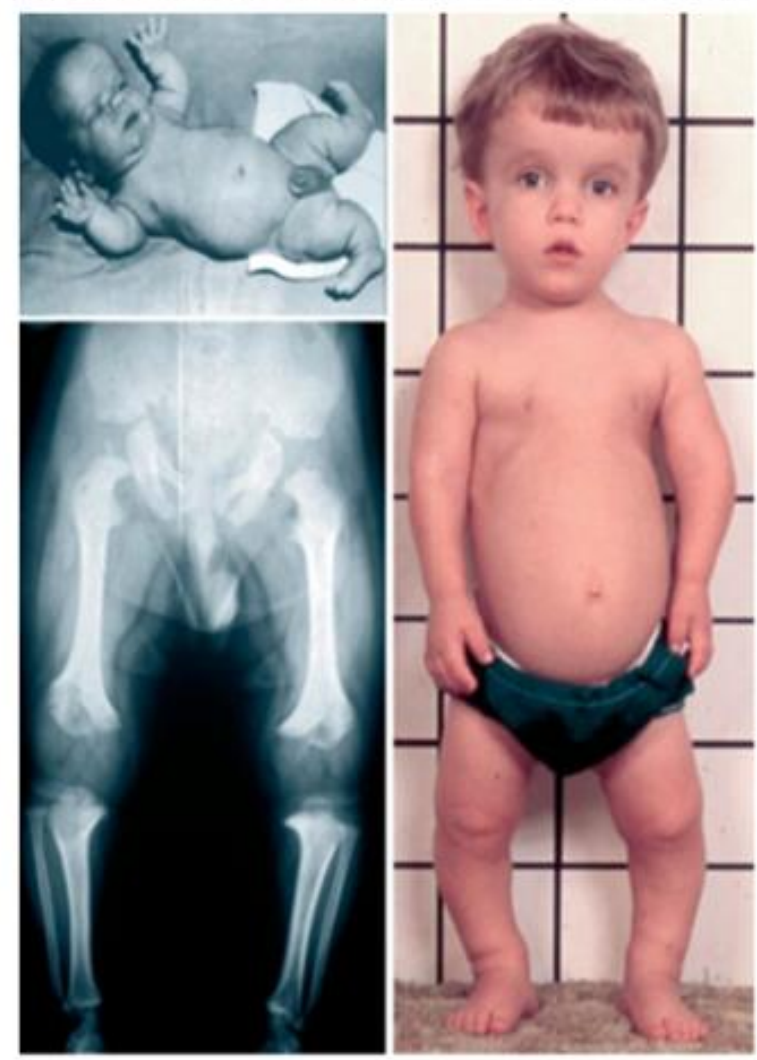


os quatorze meses de vida e de andar independentemente por trinta meses (31).

A cifose acentuada pode ser suficiente para causar a cifose do tipo Gibbus, que pode progredir com o desenvolvimento, causando compressão da medula espinhal (24). Esta complicação pode gerar sintomas como claudicação, dor lombar, cólicas e alterações do trato gastrointestinal, incluindo mudanças no peristaltismo e deficiências esfincterianas (24, 33). Se houver uma vértebra hipoplásica nesse local, os resultados do Gibbus e a compressão da medula nessa região podem ser antecipados (28). Associada à cifose, foi percebida uma prevalência significativa da escoliose na população acondroplásica. Em indivíduos normais, a escoliose apresentou uma incidência de 3\%, enquanto que, nos afetados, ela foi de $60 \%$. Dos indivíduos acondroplásicos que sofrem de escoliose, $6,1 \%$ progridem até uma angulação moderada a severa (34).

Além desta, a lordose também é muito prevalente. Alterações significativas nos parâmetros sagitais da coluna ocorrem precocemente na vida do acondroplásico, sugerindo a importância da atenção ao alinhamento espinal, a fim de evitar sequelas graves da lordose (32). Inicialmente, a lordose varia de $25^{\circ}$ a $35^{\circ}$, progredindo conforme a idade (24). Essa curvatura se acentua simultaneamente ao decréscimo da cifose toracolombar, sendo mais evidente na posição ortostática, ao contrário da cifose, mais evidente na posição sentada $(24,33)$. Ela ocorre devido a uma rotação anterior da pelve na posição ortostática, estando presente em $98 \%$ dos adultos (33).

O sacro, nos acondroplásicos, é estreito e baixo, possuindo uma articulação aguda com a região lombar da coluna. Essa angulação é crescente e o plano do sacro torna-se progressivamente mais horizontal com 0 envelhecimento (Figura 2) $(6,14)$. Em consequência disso, o cóccix também é horizontalizado. Já a pelve do recém-nascido tem uma configuração diagnóstica, apresentando um ílio quadrado, com arredondamento das extremidades em uma projeção frontal (28). Sua região inferior é curta e, portanto, a incisura isquiática maior é curta $(28,19)$. A margem inferior é horizontal, sem a inclinação normal (28). Ílios, ísquios e púbis são hipoplásicos, com ilíacos planos. A margem superior do acetábulo é horizontalizada (7), com esporões característicos (9). Os ossos púbicos e isquiáticos são curtos e rebaixados e a configuração pélvica geral é curta e ampla. O estreitamento anteroposterior da entrada da pelve impede as mulheres acondroplásicas de terem filhos por parto normal (28).

O corpo do ílio é mais curto pela diminuição da borda medial e da linha iliopectínea (35). As cristas ilíacas apresentaram crescimento normal, com espessamento da cartilagem trirradiada do acetábulo. A porção voltada ao ísquio apresentou tamanho encurtado, ao contrário da porção púbica, alongada. $O$ crescimento normal da crista ilíaca faz com que ela ocupe um nível mais elevado, chegando até $1 / 5$ da quarta vértebra lombar, ultrapassando o nível do sacro (36).

Nos membros inferiores também há a presença de alterações, em que no desenvolvimento dos acondroplásicos, a formação das epífises é retardada e os ossos tubulares são curtos e grossos (6). Isso caracteriza um encurtamento rizomélico (Figura 3), com crescimento reduzido nas extremidades proximais dos membros $(19,37)$. A razão entre o comprimento do fêmur e da tíbia é especialmente afetada (7). Há ossificação perturbada da metáfise na extremidade proximal do fêmur, o que gera uma aparência convexa das placas de crescimento, com abaulamento das interfaces. A metáfise torna-se inclinada distal e lateralmente (38). O fêmur proximal apresenta-se radiolucente, pela obliquidade do crescimento cartilaginoso, que é evidente em visões laterais femorais, mostrando uma extremidade pontiaguda. Essa mesma região apresentou um aspecto quadrado ou oval em projeções frontais, que desaparece no segundo ano de vida (28).

Em radiografias laterais de recém-nascidos, o diâmetro anteroposterior é anormalmente estreito (28). E em anteriores, as metáfises apresentam-se alargadas, com uma área fina e transparente no fêmur proximal (6). Além disso,

Figura 4- Deformidades nos metacarpos e falanges, com mão em tridente (28)

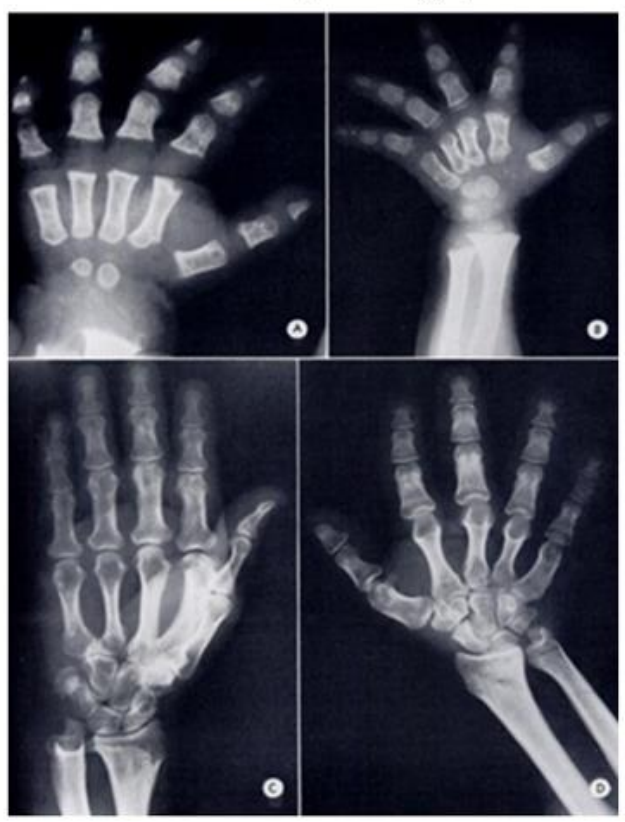

em um estudo conduzido por Khalil, et al., foram encontradas evidências de um aumento de cerca de 36\% do ângulo metáfise-epífise femoral, por meio de realização de ultrassom da vigésima à vigésima terceira semana gestacional. O ângulo mediano femoral foi o que apresentou alterações mais relevantes (39). Com o crescimento rizomélico, fica claro um encurtamento dos colos femorais (28). Em acondroplásicos, os acidentes ósseos de fixação muscular são sobressalentes, sendo que, no fêmur, o trocanter maior pode ultrapassar a linha da cabeça femoral $(28,23)$.

No fêmur distal, foram observadas alterações nos côndilos, que são estreitados, assim como a fossa intercondilar, que é mais funda $(24,33)$. Segundo Baujat et al. (6), os côndilos são frequentemente assimétricos. A placa de crescimento na extremidade distal do fêmur é côncava, com compactação da epífise no centro da cartilagem. Essa placa apresenta uma configuração de $\mathrm{V}$ invertido que se torna cada vez mais reta conforme a idade do indivíduo. Pode haver uma ossificação mais acentuada no aspecto medial do fêmur distal em comparação à região lateral, gerando uma obliquidade em 
radiografias frontais. Ainda na face lateral do fêmur distal, foi observada uma ossificação precoce no segundo semestre de vida. No segundo e terceiro anos, houve uma simétrica ossificação de ambas as metáfises femorais (28). De acordo com Horton et al. (37), há também uma protrusão da epífise na metáfise do fêmur distal, criando a chamada deformidade de Chevron.

As fíbulas nos indivíduos acondroplásicos são anormalmente longas em relação às tíbias (6). A razão fíbula/tíbia apresenta um coeficiente constante de crescimento de cerca de 0,98 em indivíduos não afetados, enquanto que, em acondroplásicos, esse coeficiente sobe para 1,08 no estágio de maturidade (40). Esse supercrescimento gera uma tíbia tensa e encurvada (28). O desenvolvimento exacerbado da fíbula aumenta seu comprimento distal, fazendo com que o maléolo lateral entre em contato com o calcâneo, limitando a eversão do pé (36).

Os joelhos das crianças com acondroplasia se hiperextendem por conta da posição alterada dos côndilos femorais em relação ao platô da tíbia (24). A forma como a fíbula se articula com a tíbia também gera uma deformidade na curvatura do membro inferior, já que com o início da

deambulação, o efeito do peso e o mau posicionamento das extremidades ósseas, a tíbia rota internamente, causando diferentes graus de Genu Varum (24, 33, 41). Essa deformidade é caracterizada por uma posição do joelho em um plano lateral, com desalinhamento tibial em relação ao fêmur, impedindo o contato entre os joelhos (41). Outra causa comum do Genu Varum é a frouxidão dos ligamentos da região genicular (42).

A inclinação média da tíbia é significativamente anterior em pacientes com acondroplasia em relação à população geral, sendo que essa diferença reduz com a progressão etária dos pacientes. A tendência do declive tibial em direção ao normal, associado à diminuição da frouxidão ligamentar e aumento do controle muscular sobre o joelho pode explicar a gradual atenuação do Genu Varum. Também foi observado um arqueamento das tíbias em relação a um menor crescimento tibial comparado à fíbula, ocorrendo em $10 \%$ das crianças de até cinco anos de idade e em $42 \%$ dos adultos (7).

Os membros superiores, da mesma forma, apresentam alterações, em que o encurtamento rizomélico também está presente, acentuando-se no úmero e estando presente em todas as idades. O úmero proximal, analisado em uma vista anterior apresenta uma aparência oval ou quadrada, com um estreitamento anteroposterior, semelhante às alterações encontradas no fêmur proximal. O colo do úmero apresentase curto e angulado em uma projeção lateral (28). Segundo Silverman (22), os acidentes ósseos são proeminentes, incluindo o tubérculo deltoide (36).

É descrito também um deslocamento umeral anterior em repouso nas crianças maiores de quatro anos, com arqueamento posterior do úmero distal. Essa particularidade limita a extensão do cotovelo em $70 \%$ dos indivíduos afetados (7). A cabeça do úmero pode apresentar formatos variados, facilitando a luxação na fossa glenoide, principalmente no sentido anteroinferior. A articulação em si apresenta grande mobilidade, mas os movimentos do ombro são limitados em cerca de $20^{\circ}$ a $60^{\circ}$ (14).

O rádio e a ulna apresentam comprimento aumentado em relação ao tamanho do úmero. Diante disso, a cabeça radial é mais achatada e deformada, o que pode resultar em limitação da movimentação do cotovelo (28). Essa limitação frequentemente causa subluxações da cabeça do rádio nos primeiros anos de vida (7). São comuns também as dores nos punhos, por subluxação da articulação radioulnar distal (24, 33).

Nas mãos dos acondroplásicos, há deformidade dos metacarpos. No entanto, a mudança mais marcante ocorre nas falanges proximais e média, que são curtas, largas, cônicas e com uma aparência maciça (28). O primeiro e quinto dedos apresentam posições normais, já o segundo, terceiro e quarto aproximam-se em relação à linha média (43). Isso evidencia uma incapacidade na oposição do terceiro e quarto dígitos (37).

Ocorre também um grau acentuado de desvio dos dedos, com afastamento do terceiro e quarto dedos (28). Esse afastamento caracteriza a mão em tridente (Figura 4) (14). Além disso, é muito perceptível a assimetria na formação das falanges proximais do lado ulnar e radial, sendo o lado ulnar mais desenvolvido (23). Em avaliações radiográficas do punho, mão e dedos, percebe-se um retardo do desenvolvimento, sendo a idade óssea incompatível com a idade cronológica. Porém, na adolescência, a maturação óssea é acelerada, chegando aos níveis referenciais de crescimento (44).

Em relação a alterações no tórax, a caixa torácica é considerada relativamente pequena, particularmente no diâmetro anteroposterior, devido à lentidão no desenvolvimento das costelas. Nelas, é perceptível uma aparência em concha das extremidades anteriores, que é mais evidenciada nos acondroplásicos infantis (28). Em visão lateral, apresentam-se curtas, com extremidades anteriores cupuliformes aumentadas e alargadas $(6,20)$.

As costelas são complacentes, causando, em alguns casos, uma má interpretação de estresse respiratório. Também foram observados vestígios de indentações laterais no tórax e pectus excavatum (14). Apesar das costelas serem mais curtas, a caixa torácica é ampla, pelo maior comprimento das cartilagens costais $(24,33)$. As alterações descritas para cada segmento corporal estão resumidas na Tabela 1.

\section{DISCUSSÃO}

Os artigos analisados não apresentaram divergências entre si. Os resultados encontrados foram válidos e relevantes para obter uma caracterização da doença e permitir a execução de diagnósticos e tratamentos. A acondroplasia equivale, nos Estados Unidos, a cerca de $90 \%$ dos casos de nanismo (45). As alterações mais evidentes foram encontradas nos ossos do crânio, coluna vertebral, pelve, membros e tórax.

Com base nas alterações descritas, critérios diagnósticos podem ser estabelecidos e é possível determinar as 
principais alterações ósseas e radiográficas descritas na literatura em pacientes com acondroplasia. Os aspectos clínicos envolvem tanto achados clínicos quanto radiológicos. Estes estão relacionados a alterações na base do crânio. No estudo conduzido por Júnior, foi observada uma incidência de $100 \%$ de diminuição do diâmetro transverso do forame magno e de $96 \%$ de estreitamento no sentido anteroposterior. Houve hipoplasia do clivo em $88 \%$ dos casos e, em $25 \%$ dos casos, instabilidade atlanto-occipital (7).

Nos acondroplásicos, a razão entre o viscerocrânio e o neurocrânio apresenta-se reduzida em relação à proporção em indivíduos normais, que é de 1/8 (13). No aspecto clínico, a dentição apresenta-se apinhada e sem alinhamento, levando à maloclusão. Ainda no crânio é observada uma ponte nasal deprimida, osso frontal proeminente e redução do tamanho da base do crânio (14).

Critérios diagnósticos estão também relacionados a modificações na coluna vertebral. Dentre elas, incluem-se mudanças na curvatura normal, evidenciando-se a cifose lombar e hiperlordose a partir do primeiro ano de vida. Variações vertebrais radiológicas abrangem uma diminuição progressiva no sentido descendente da distância interpedicular na coluna lombar (46). Foi observada estenose espinal, em especial a nível de C2 em 92\% dos casos (7).

As principais alterações contempladas na pelve são radiológicas, incluindo a espinha isquiática pequena e deprimida e o ílio em formato quadrado, com as extremidades arredondadas. Observações clínicas e radiológicas dos membros destacam o encurtamento rizomélico (46). Conforme estudo publicado por Júnior (7), foi observada uma prevalência dessa característica em $71 \%$ da amostra. Os ossos tubulares são encurtados e as metáfises alargadas. Os dedos são mais curtos e as mão são em tridente. As modificações encontradas no tórax não são evidentes o suficiente para servirem de critério diagnóstico (46).

Todos esses aspectos associados podem facilitar um diagnóstico ainda no pré-natal, mas somente em indivíduos com pais acondroplásicos. Em outros fetos é difícil fazer essa determinação, já que esse diagnóstico precoce não apresentará um alto índice de confiabilidade. Mesmo nesses casos, a observação gestacional só começa a apresentar alterações após a vigésima semana de gestação (39). Após o nascimento, o exame físico completo analisando as características fenotípicas, associadas às alterações radiológicas já descritas confirmam o diagnóstico.

O presente estudo, entretanto, encontrou algumas limitações, das quais se destacam a escassez de artigos recentes sobre o tema e que agrupassem o conhecimento sobre alterações ósseas como um todo, de forma que alguns trabalhos utilizados eram antigos. Assim, esta pesquisa se mostra relevante ao atualizar as informações sobre o diagnóstico da acondroplasia com base nas deformidades ósseas vistas pelos achados clínicos e radiológicos, agrupando-as em apenas um texto.

\section{CONCLUSÃO}

As principais deformidades ósseas da acondroplasia referemse à ossificação endocondral, principalmente do crânio, coluna vertebral, pelve, membros e tórax, sendo estas importantes para o diagnóstico da doença. Devido à dificuldade de encontrar trabalhos sintetizados que abrangessem todas as modificações vistas nesses indivíduos, o presente estudo oferece uma complementação à literatura existente de forma resumida sobre o tema. Há, entretanto, a necessidade da realização de pesquisas melhor estruturadas sobre a acondroplasia, feitas prospectivamente, com maiores amostras e que correlacionem os achados radiológicos e clínicos com as alterações funcionais dos pacientes, o que poderá auxiliar no desenvolvimento de soluções para os acondroplásicos.uma caracterização da doença e permitir a execução de diagnósticos e tratamentos. A acondroplasia equivale, nos Estados Unidos, a cerca de $90 \%$ dos casos de nanismo (45). As alterações mais evidentes foram encontradas nos ossos do crânio, coluna vertebral, pelve, membros e tórax.

\section{CONFLITO DE INTERESSE}

Os autores declaram que não há nenhum conflito de interesse presente no estudo.

\section{FINANCIAMENTO}

Os autores declaram que não houve fontes de financiamento.

\section{REFERÊNCIAS}

1. Castro A, Gutiérrez A, Rodríguez LF, Pineda T, Velasco $\mathrm{H}$, Arteaga $\mathrm{C}$, et al. Análisis Mutacional De La Acondroplasia En 20 Pacientes Colombianos. Rev la Fac Med. 2010 Jul-Set; 58(3):185-90.

2. Couto CM. Acondroplasia: Características esqueléticas e cefalométricas da face [Tese de Mestrado]. Viseu: Instituto de Ciências da Saúde, Universidade Católica Portuguesa; 2017; 92 p.

3. Moore KL, Persaud TVN, Torchia MG. Embriologia básica. Rio de Janeiro: Elsevier; 2016. 384 p.

4. Orioli IM, Castilla EE, Barbosa-Neto JG. The birth prevalence rates for the skeletal dysplasias. J Med Genet. 1986 Ago;23(4):328-32.

5. Calandrelli R, Panfili M, D’Apolito G, Zampino G, Pedicelli A, Pilato $F$, et al. Quantitative approach to the posterior cranial fossa and craniocervical junction in asymptomatic children with achondroplasia. Neuroradiology. 2017 Out; 59(10):1031-41.

6. Baujat G, Legeai-Mallet L, Finidori G, Cormier-Daire V, Le Merrer M. Achondroplasia. Best Pract Res Clin Rheumatol. 2008 Mar; 22(1):3-18.

7. Júnior ALC. Alterações no esqueleto axial e alterações neurológicas na Acondroplasia [Tese de Mestrado]. Belo Horizonte: Universidade Federal de Minas Gerais, Faculdade de Medicina; 2014. 110 p. 
8. Kliegman RM, Stanton BF, Geme JS, Schor N, Behrman RE. Nelson Tratado de Pediatria. São Paulo: Elsevier; 2013. 2872 p.

9. Fagen KE, Blask AR, Rubio EI, Bulas DI. Achondroplasia in the premature infant: An elusive diagnosis in the neonatal intensive care unit. AJP Rep. 2017 Jan;7(1):e812.

10. Spranger JW, Brill PW, Poznanski A. Bone Dysplasias: An Atlas of Genetic Disorders of Skeletal Development. Nova York: Oxford University Press; 2003. 632 p.

11. Albino FP, Wood BC, Oluigbo CO, Lee AC, Oh AK, Rogers GF. Achondroplasia and multiple-suture craniosynostosis. J Craniofac Surg. 2015 Jan; 26(1):2225.

12. Cardoso R, Ajzen S, Andriolo AR, Oliveira JX, Andriolo A. Analysis of the cephalometric pattern of Brazilian achondroplastic adult subjects. Dental Press J Orthod. 2012 Dez; 17(6):118-29.

13. Moore KL, Dalley AF, Agur RMA. Anatomia Orientada para a Clínica. Rio de Janeiro: Guanabara Koogan; 2014. $1136 \mathrm{p}$.

14. Pauli RM. Achondroplasia: A comprehensive clinical review. Orphanet J Rare Diseases. 2019 Jan; 14(1):1-49.

15. McDonald RE. Dentistry for the Child and Adolescent. St. Louis: Mosby; 1974. 561 p.

16. Cardoso R, Ajzen S, Maria L, Ramos S, Costa C, Oliveira JX. Características cranianas, faciais e dentárias em indivíduos acondroplásicos. Rev Inst Ciênc Saúde. 2009 Abr-Jun; 27(2):171-5.

17. Björk A. Cranial base development: A follow-up x-ray study of the individual variation in growth occurring between the ages of 12 and 20 years and its relation to brain case and face development. Am J Orthod. 1955 Mar; 41(3):198-225.

18. Gordon N. The neurological complications of achondroplasia. Brain Dev. 2000 Jan; 22(1):3-7.

19. Richette P, Bardin T, Stheneur C. Achondroplasia: From genotype to phenotype. Jt Bone Spine. 2008 Mar; 75(2):125-30.

20. Sargar KM, Singh AK, Kao SC. Imaging of skeletal disorders caused by fibroblast growth factor receptor gene mutations. Radiographics. 2017 Out; 37(6):181330 .

21. Chiba S, Abe S, Ohmori I. Oral manifestations of achondroplasia: a case report. Tsurum Shigaku. 1976 Jun; 2(1):35-43.
22. Silverman FN. Human Achondroplasia. 1a edição. New York: Plenum Press; c1988. Capítulo 5, Radiologic Features of Achondroplasia. p. 31-44.

23. Bailey JA. Orthopaedic aspects of achondroplasia. J Bone Joint Surg Am. 1970 Out; 52(7):1285-301.

24. Kopits SE. Human Achondroplasia. 1a edição. New York: Plenum Press; c1988. Capítulo 28, Orthopedic Aspects of Achondroplasia in Children. p. 189-97.

25. Canson BS, Groves M, Yassari R. Schmidek and Sweet Operative Neurosurgical Techniques, 6a edição. Philadelphia: Elsevier/Saunders; c2012. Capítulo 184, Neurologic Problems of Spine in Achondroplasia. p. 2091-9.

26. Thomas JN. Partial upper airway obstruction and sleep apnea. J Laryngol Otol. 1978 Jan; 92(1):41-6.

27. Elwood ET, Burstein FD, Graham L, Williams JK, Paschal M. Midface distraction to alleviate upper airway obstruction in achondroplastic dwarfs. Cleft PalateCraniofacial J. 2003 Jan; 40(1):100-3.

28. Langer LO, Baumann PA, Gorlim RJ, Robert J. Achondroplasia. American J Roentgenology. 1967 Ago; 100(1):12-26.

29. Hunter AGW, Bankier A, Rogers JG, Sillence D, Scott CI. Medical complications of achondroplasia: A multicentre patient review. J Med Genet. 1998 Set; 35(9):705-12.

30. Borkhuu B, Nagaraju DK, Chan G, Holmes L, MacKenzie WG. Factors related to progression of thoracolumbar kyphosis in children with achondroplasia: A retrospective cohort study of forty-eight children treated in a comprehensive orthopaedic center. Spine (Phila Pa 1976). 2009 Jul; 34(16):1699-705.

31. Margalit A, McKean G, Lawing C, Galey S, Ain MC. Walking out of the Curve: Thoracolumbar Kyphosis in Achondroplasia. J Pediatr Orthop. 2018 Nov-Dez; 38(10):491-7.

32. Abousamra O, Shah SA, Heydemann JA, Kreitz TM, Rogers KJ, Ditro C, et al. Sagittal spinopelvic parameters in children with achondroplasia. Spine Deform. 2019 Jan;7(1):163-70.

33. Kopits SE. Human Achondroplasia. 1a edição. New York: Plenum Press; c1988. Capítulo 34, Thoracolumbar Kyphosis and Lumbosacral Hyperlordosis in Achondroplastic Children. p. 241-55.

34. Khan BI, Yost MT, Badkoobehi H, Ain MC. Prevalence of scoliosis and thoracolumbar kyphosis in patients with achondroplasia. Spine Deform. 2016 Mar;4(2):145-8.

35. Spranger JW. Human Achondroplasia. 1a edição. New York: Plenum Press; c1988. Capítulo 14, The skull in achondroplasia. p. 103-7. 
36. Ponseti IV. Human Achondroplasia. 1a edição. New York: Plenum Press; c1988. Capítulo 15, Bone formation in achondroplasia. p. 109-22.

37. Horton WA, Hall JG, Hecht JT. Achondroplasia. Lancet. 2007 Jul; 370(9582):162-72.

38. Boulet S, Althuser M, Nugues F, Schaal JP, Jouk PS. Prenatal diagnosis of achondroplasia: new specific signs. Prenat Diagn. 2009 Jul;29(7):697-702.

39. Khalil A, Chaoui R, Lebek H, Esser T, Entezami M, Toms $\mathrm{J}$, et al. Widening of the femoral diaphysis-metaphysis angle at 20-24 weeks: a marker for the detection of achondroplasia prior to the onset of skeletal shortening. Am J Obstet Gynecol. 2016 Fev;214(2):291-2.

40. Ain MC, Shirley ED, Pirouzmanesh A, Skolasky RL, Leet Al. Genu varum in achondroplasia. J Pediatr Orthop. 2006 Mai-Jun;26(3):375-9.

41. McClure PK, Kilinc E, Birch JG. Growth Modulation in Achondroplasia. J Pediatr Orthop. 2017 Set; 37(6):e3847.

42. Brooks JT, Bernholt DL, Tran KV, Ain MC. The tibial slope in patients with achondroplasia: Its characterization and possible role in genu recurvatum development. $\mathrm{J}$ Pediatr Orthop. 2016 Jun;36(4):349-54.

43. Biesecker LG, Aase JM, Clericuzio C, Gurrieri F, Temple IK, Toriello $\mathrm{H}$. Elements of morphology: Standard terminology for the hands and feet. Am J Med Genet Part A. 2009 Jan; 149(1):93-127.

44. Ornitz DM, Legeai-Mallet L. Achondroplasia: Development, Pathogenesis, and Therapy. Developmental Dynamics. 2016 Abr; 246(4):291-309.

45. Waller DK, Correa A, Vo TM, Wang Y, Hobbs C, Langlois $\mathrm{PH}$, et al. The Population-Based Prevalence of Achondroplasia and Thanatophoric Dysplasia in Selected Regions of the US. Am J Med Genet A. 2018 Jul;146(18):2385-9.

46. Cialzeta D. Acondroplasia: una mirada desde la clínica pediátrica. Rev Hosp Niños BAires. 2009 Mar; 51(231):16-22. 